\title{
Comparative Physiology
}

National Cancer Institute

\section{Source}

National Cancer Institute. Comparative Physiology. NCI Thesaurus. Code C16991.

The study of similarities and differences of the vital processes of different organisms. 